\title{
Modeling of Sulfate Double-salts in Nuclear Wastes
}

\author{
B. Toghiani, J. S. Lindner \\ Mississippi State University \\ P.O. Box 5325 \\ Mississippi State, MS 39762 \\ C. F. Weber, R. D. Hunt \\ Oak Ridge National Laboratory \\ P.O. Box 2008 \\ Oak Ridge, TN 37831-6370
}

Date Published: October 2000

Prepared by the OAK RIDGE NATIONAL LABORATORY

Oak Ridge, Tennessee 37831-6370 managed by

UT-BATTELLE, LLC

for the

U.S. DEPARTMENT OF ENERGY

under contract DE-AC05-00OR22725 



\section{CONTENTS}

$\underline{\text { Page }}$

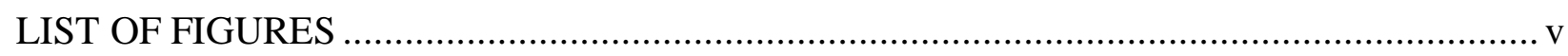

LIST OF TABLES . . ................................................................................................ vii

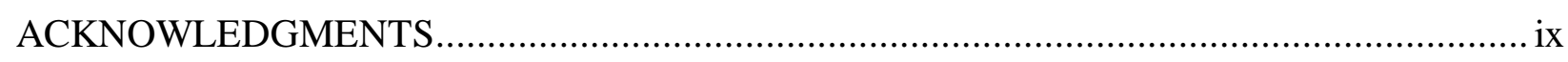

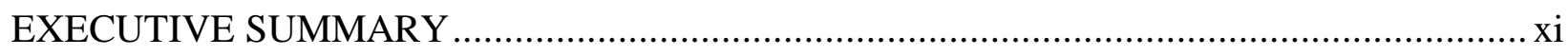

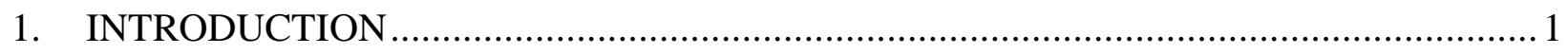

2. COMPARATIVE CALCULATIONS FOR THR DOUBLE SALT SYSTEMS .....................5

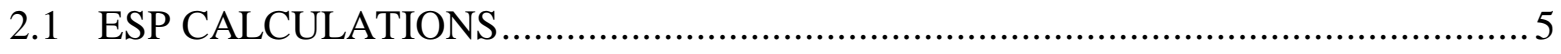

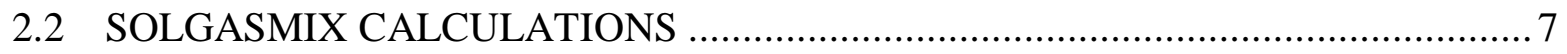

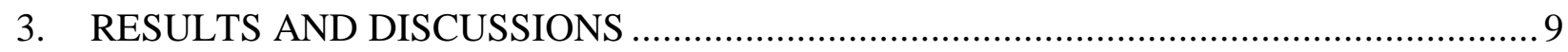

3.1 SODIUM-NITRATE-SULFATE SYSTEM ..................................................... 9

$3.2 \quad$ SODIUM-FLUORIDE-SULFATE SYSTEM..................................................... 13

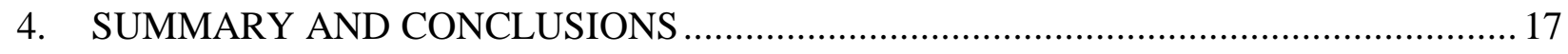

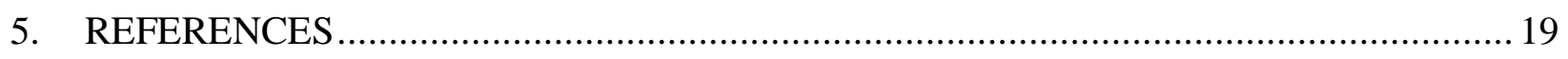

APPENDIX A — PARAMETERS FOR SOLGASMIX MODEL ........................................... 21 



\section{LIST OF FIGURES}

$\underline{\text { Figure }}$

$\underline{\text { Page }}$

1. Solubility envelope for the sodium-fluoride-phosphate system at $25^{\circ} \mathrm{C}$ in water ............. 2

2. Solubility envelope for the sodium-nitrate-sulfate system at $25^{\circ} \mathrm{C}$ in water ................... 6

3. Solubility envelope for the sodium-nitrate-sulfate system at $25^{\circ} \mathrm{C}$ in $1-3 m$ hydroxide

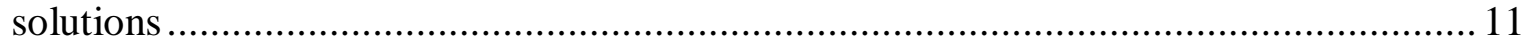

4. ESP and SOLGASMIX predictions for the sodium-nitrate-sulfate system at $50^{\circ} \mathrm{C}$....... 12

5. Comparison of the solubility envelope for the sodium-fluoride-sulfate system at $25^{\circ} \mathrm{C}$... 14

6. Comparison of the solubility envelope for the sodium-fluoride-sulfate system at $50^{\circ} \mathrm{C}$... 15 



\section{LIST OF TABLES}

Table $\quad$ Page

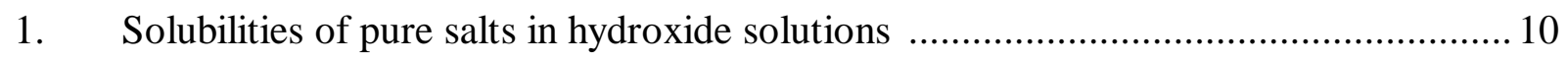

A.1. Coefficients for Gibbs energy of formation ..................................................... 23

A.2. Coefficients for Pitzer parameters ............................................................ 24 



\section{ACKNOWLEDGMENTS}

This task was sponsored by the U.S. Department of Energy through the Office of Science and Technology's Tank Focus Area. The Environmental Simulation Program predictions were performed at Mississippi State University in the Diagnostic Instrumentation and Analysis Laboratory. Additional support from the Department of Energy through Cooperative Agreement DE-FC26-98FT40395 is gratefully acknowledged. The SOLGASMIX calculations were performed at the Oak Ridge National Laboratory under the auspices of the Computational Physics and Engineering Division and the Chemical Technology Division. Oak Ridge National Laboratory is managed by UT-Battelle, LLC, under contract DE-AC05-00OR22725. 



\section{EXECUTIVE SUMMARY}

Due to limited tank space at Hanford and Savannah River, the liquid nuclear wastes or supernatants have been concentrated in evaporators to remove excess water prior to the hot solutions being transferred to underground storage tanks. As the waste solutions cooled, the salts in the waste exceeded the associated solubility limits and precipitated in the form of saltcakes. The initial step in the remediation of these saltcakes is a rehydration process called saltcake dissolution. At Hanford, dissolution experiments have been conducted on small saltcake samples from five tanks. Modeling of these experimental results, using the Environmental Simulation Program (ESP), are being performed at the Diagnostic Instrumentation and Analysis Laboratory (DIAL) at Mississippi State University. The River Protection Project (RPP) at Hanford will use these experimental and theoretical results to determine the amount of water that will be needed for its dissolution and retrieval operations.

A comprehensive effort by the RPP and the Tank Focus Area continues to validate and improve the ESP and its databases for this application. The initial effort focused on the sodium, fluoride, and phosphate system due to its role in the formation of pipeline plugs. In FY 1999, an evaluation of the ESP predictions for sodium fluoride, trisodium phosphate dodecahydrate, and natrophosphate clearly indicated that improvements to the Public database of the ESP were needed. One of the improvements identified was double salts. The inability of any equilibrium thermodynamic model to properly account for double salts in the system can result in errors in the predicted solid-liquid equilibria (SLE) of species in the system.

The ESP code is evaluated by comparison with experimental data where possible. However, data does not cover the range of component concentrations and temperatures found in many tank wastes. Therefore, comparison of ESP with another code is desirable, and may illuminate problems with both. For this purpose, the SOLGASMIX code was used in conjunction with a small private database developed at ORNL. This code calculates thermodynamic equilibria through minimization of Gibbs Energy, and utilizes the Pitzer model for activity coefficients.

The sodium nitrate-sulfate double salt and the sodium fluoride-sulfate double salt were selected for the FY 2000 validation study of ESP. Even though ESP does not include the sulfate-nitrate double salt, this study found that this omission does not appear to be a major consequence. In this case, the solubility predictions with and without the sulfate-nitrate double salt are comparable. In contrast, even though the sulfate-fluoride double salt is included within the ESP databank, comparison to previous experimental results indicates that ESP underestimates solubility. Thus, the prediction for the sulfate-fluoride system needs to be improved. A main consequence of the inability to accurately predict the SLE of double salts is its impact on the predicted ionic strength of the solution. The ionic strength has been observed to be an important factor in the formation of pipeline plugs. To improve the ESP prediction, solubility tests on the sulfate-fluoride system are underway at DIAL, and these experimental results will be incorporated into the Public database by OLI System, Inc. 
Preliminary ESP simulations also indicated difficulties with the SLE prediction for anhydrous sodium sulfate. The Public database for the ESP does not include fundamental parameters for this solid in mixed solutions below $32.4^{\circ} \mathrm{C}$. The limitation, in the range of anhydrous sodium sulfate, leads to convergence problems in ESP and to inaccurate predictions of solubility near the invariant point when sodium sulfate decahydrate and other salts, such as sodium nitrate, were present. These difficulties were partially corrected through the use of an additional database.

In conclusion, these results indicate the need for experimental data at temperatures above $25^{\circ} \mathrm{C}$ and in solutions containing both nitrate and hydroxide. Furthermore, the validation and documentation of different ESP input data sets is still a crucial need. With judicious use, ESP can still provide valuable guidance for water processing operations. However, this study has identified several improvements and corrections, which could be implemented immediately. 


\section{INTRODUCTION}

The nuclear wastes in the underground tanks at Hanford, Savannah River, and other Department of Energy (DOE) sites are comprised of sludge, saltcake, and supernatants. The supernatants and the solutions from saltcake dissolution are typically saturated with respect to several salts. As these wastes are transferred and processed, changes in the equilibrium conditions will occur. At Hanford and Savannah River these changes have led to unwanted solids that have plugged transfer lines. While most of these solids will consist of simple cation-anion pairs, the formation of double salts is possible. For example, possible precipitants for a solution of sodium, fluoride, and phosphate include sodium fluoride ( $\mathrm{NaF})$, trisodium phosphate dodecahydrate $\left(\mathrm{Na}_{3} \mathrm{PO}_{4} \cdot 12 \mathrm{H}_{2} \mathrm{O}\right)$, and natrophosphate $\left(2 \mathrm{Na}_{3} \mathrm{PO}_{4} \cdot \mathrm{NaF} \cdot 19 \mathrm{H}_{2} \mathrm{O}\right)$. It is important to note that the Hanford tanks contain approximately 61,000 and 62,000 moles of fluoride and phosphate, respectively. Therefore, each of the possible solids would be expected. In fact, both trisodium phosphate dodecahydrate (TSPD) and natrophosphate have been identified in samples of the Hanford tank wastes. 1,2 Several of the pipeline plugs at Hanford were probably due to the formation of the TSPD needle crystals. The natrophosphate forms a gel, and a study on its role in the formation of pipeline plugs is underway ${ }^{3}$ Due to the importance of these phosphates in the transport of the nuclear waste, researchers at Oak Ridge National Laboratory (ORNL) used the SOLGASMIX code to model the solubility of trisodium phosphate as well as the sodium, fluoride, and phosphate system. ${ }^{5}$ A special adaptation of the SOLGASMIX code $e^{6,7}$ was used to calculate the chemical equilibria. This code was modified to include electrolyte solutions, and it utilizes the Pitzer model for activity coefficients $\stackrel{8}{8}$ Similar calculations have been performed at the Diagnostic Instrumentation and Analysis Laboratory (DIAL) at Mississippi State University using the Environmental Simulation Program (ESP). 9

While nearly all of the simulation programs can predict the behavior of simple salts, the codes and their databases may not be adequately equipped to simulate the solubilities of the double salts. As shown in Fig. 1, the failure to include the fundamental thermodynamic data for the natrophosphate double salt (top dashed line, hypothetical data) would severely over-predict the ionic concentrations as compared to the actual experimental data and associated simulation result (solid line and data points). A difficulty with overprediction of one ionic species is the underprediction of the amount of solids in the system. Retrieval operations based on a lower than expected solids loading could severely impact plant operations through additional solids deposition. Similarly, more dilution water would be required if the amount of solids were overpredicted, leading to large waste volumes.

The River Protection Project (RPP) at Hanford uses the ESP to plan and model its waste transfers and treatments. In particular, ESP will be used to predict the amount of water that will be needed for the saltcake dissolution. Therefore, the SOLGASMIX and ESP predictions for the sodium, fluoride, and phosphate system at $25^{\circ} \mathrm{C}$ were compared in an effort to validate the ESP and its Public database. 10 This evaluation indicated that improvements to the ESP database for the sodium-fluoride-phosphate system were needed. A series of solubility experiments 


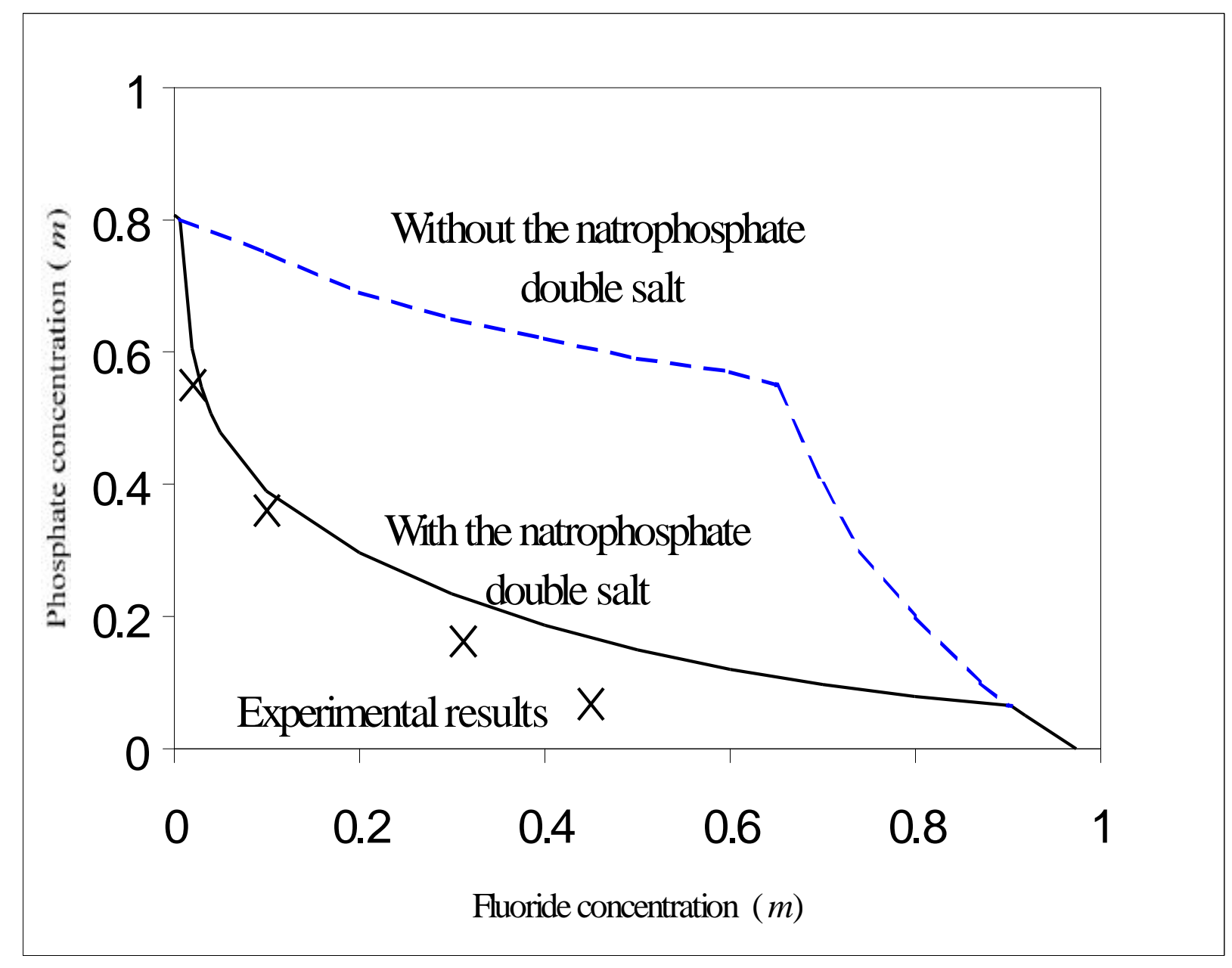

Fig. 1. Solubility envelope for the sodium-fluoride-phosphate system at $25^{\circ} \mathrm{C}$ in water.

on the sodium-fluoride-phosphate system were performed in order to improve the ESP database and its predictions. ${ }^{9}$

Due to the presence of multiple anions in the Hanford and Savannah River wastes, it is imperative to determine the accuracy of the ESP predictions for these different systems. If ESP underestimates the solubility of a particular double salt species, the predictions of the formation of other salt species may be in error. For example, overestimation of the solubility of the sodium fluoride-sulfate double salt would produce an artificial increase in the concentration of fluoride in the liquid phase. In the presence of sufficient phosphate, this fluoride would then be available to precipitate as the natrophosphate double salt. This reduction in phosphate concentration could 
lead to underestimation of the amount of TSPD that could potentially precipitate and plug a pipeline.

For FY 2000, the Tank Focus Area and the RPP selected two double salts for the comparison study on the ESP and SOLGASMIX predictions. The sodium nitrate-sulfate double salt $\left(\mathrm{NaNO}_{3} \cdot \mathrm{Na}_{2} \mathrm{SO}_{4} \cdot 2 \mathrm{H}_{2} \mathrm{O}\right)$ was chosen because it is a major component in the Hanford tank TX-113 saltcake samples that were used in dissolution experiments 11 This observation should not be surprising because $11 \%$ of the total site sulfate inventory of 40,000 moles is in tank TX-113. The sodium fluoride-sulfate double salt $\left(\mathrm{NaF} \cdot \mathrm{Na}_{2} \mathrm{SO}_{4}\right)$ was also selected because it has been identified as one of the precipitates in Savannah River waste simulant. Sulfate, as well as phosphate, can have a dramatic impact on ionic strength, which plays a key role in the formation of pipeline plugs 12 



\section{COMPARATIVE CALCULATIONS OF THE SULFATE DOUBLE SALTS}

The computational approaches for the ESP and SOLGASMIX are somewhat different. In calculating chemical equilibrium, SOLGASMIX uses minimization of Gibbs Energy, while ESP usually solves for the simultaneous equilibrium of many individual reactions (the KFIT routine). (Actually, ESP is able to use Gibbs Energy minimization, but this approach is not the default; the associated database is incomplete and is at times inconsistent with the results using KFIT.) In addition, SOLGASMIX uses the Pitzer model for activity coefficients, ${ }^{8}$ while ESP currently uses the Bromley method.

The ESP code is accompanied by several extensive databases, each of which was developed for a particular application such as corrosion or geochemistry. The ESP model always calls its "Public" databank. If an additional databank is selected, the fundamental data in the specialized database is used for the species common to both databases. No modifications to the ESP code (version 6.2) or its database were made. In contrast, SOLGASMIX does not have an extensive database. However, the SOLGASMIX code is available for modifications, and experimental results can easily be added.

\subsection{ESP CALCULATIONS}

Thermodynamic data for the nitrate-sulfate double salt is not currently present in the ESP databases. Nevertheless, the solubility of the sodium-nitrate-sulfate system was closely predicted when the appropriate database was selected. Simulations that only used the Public database yielded unrealistic results as shown in Fig. 2.

A preliminary attempt to model the dissolution of saltcake samples from tank TX-113 indicated that the Public database does not adequately predict the solubility of the anhydrous sodium sulfate at elevated ionic strength. In contrast to the experimental results, $\frac{12}{2}$ the ESP with its Public database predicted that the sodium sulfate would remain soluble and would not precipitate. For this reason, ESP predictions of sodium sulfate were conducted using a second thermodynamic database, which is entitled "Na2snacl." The manufacturer of the ESP, OLI System, Inc., provided the Na2snacl database after the discrepancies with the sulfate solubility were discovered using the Public database. This database was not previously included in the base ESP installation software.

The sodium fluoride-sulfate system was also investigated using ESP. Thermodynamic data for the sodium fluoride-sulfate double salt is provided in the ESP Public database so modifications were not needed to obtain the predictions at $25^{\circ} \mathrm{C}$. However, the prediction of this species in the solid phase, using data in the Public database, is restricted to temperatures from $20-40^{\circ} \mathrm{C}$. This restricted temperature range is invoked due to the limited experimental data on which the equilibrium constant expression is based. Therefore, it was necessary to extend the 
range of applicability to $50^{\circ} \mathrm{C}$ in order to conduct ESP predictions at the elevated temperature. While this extension introduces some uncertainty, solubility experiments are currently underway at Mississippi State University in order to verify or correct predictions at higher temperatures. Thermodynamic data in the $\mathrm{Na} 2$ nacl database was used for both of the simple sulfate salts-anhydrous sodium sulfate $\left(\mathrm{Na}_{2} \mathrm{SO}_{4}\right)$ and sodium sulfate decahydrate $\left(\mathrm{Na}_{2} \mathrm{SO}_{4} \cdot 10 \mathrm{H}_{2} \mathrm{O}\right)$. For the partitioning of the sulfate into the solid phase, the Na2snacl database has proven to be more reliable than the Public database, based upon earlier calculations for the sodium-nitrate-sulfate system and for the dissolution of saltcake from tank TX-113.

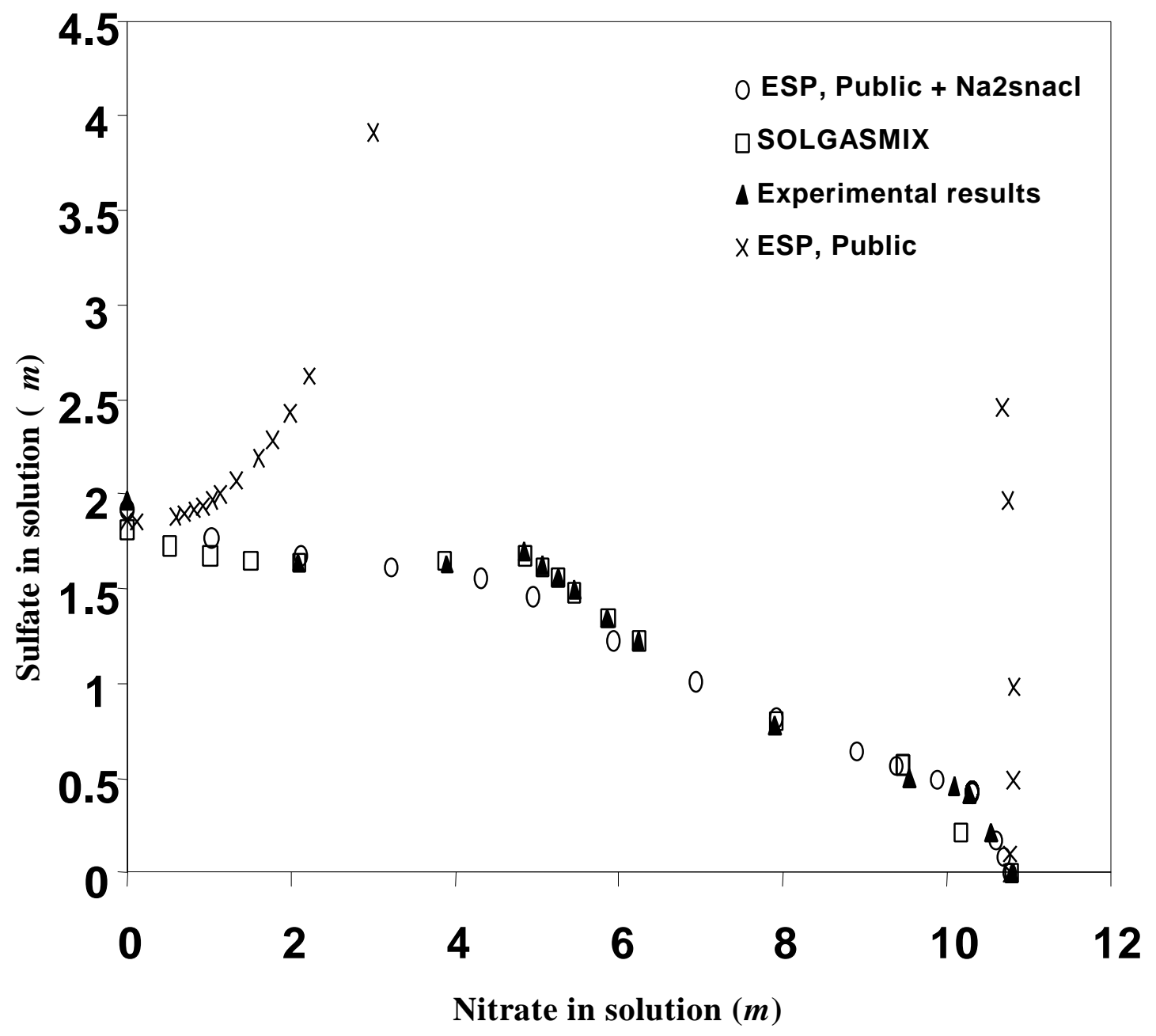

Fig. 2. Solubility comparison for the sodium-nitrate-sulfate system at $25^{\circ} \mathrm{C}$ in water. 


\subsection{SOLGASMIX CALCULATIONS}

The modeling of sulfate systems must include the behavior of other principal anions such as hydroxide and nitrate that are present in the nuclear waste solutions. Therefore, the initial focus of the model development was on the sodium-sulfate-hydroxide and sodium-sulfate-nitrate systems. Fortunately, the experimental solubilities of both ternary systems are available from $0-100^{\circ} \mathrm{C} .13$ Each parameter of interest was represented by the following equation:

$$
\mathrm{F}(\mathrm{T})=\mathrm{A}+\mathrm{B}\left(\mathrm{T}-\mathrm{T}_{0}\right)+\mathrm{C}\left(1 / \mathrm{T}_{0}-1 / \mathrm{T}\right)+\mathrm{D} \ln \left(\mathrm{T} / \mathrm{T}_{0}\right)+\mathrm{E}\left(\mathrm{T}^{2}-\mathrm{T}_{0}{ }^{2}\right)
$$

where $\mathrm{T}_{0}=298.15 \mathrm{~K}$. From $0-100^{\circ} \mathrm{C}$, only one or two of the temperature coefficients is usually required to produce acceptable agreement with experiment.

The binary Pitzer parameters for sodium-hydroxide, sodium-sulfate, sodium-nitrate, and sodium-fluoride have been determined previously 12 The Gibbs energies of formation for the aqueous ions were obtained from the HSC database. 14 Ternary Pitzer parameters and Gibbs energies of formation for solids were determined by nonlinear regression of solubility data. Since anhydrous sodium sulfate and sodium sulfate decahydrate are involved in each ternary system, the Gibbs energies were fit to all solubility data simultaneously. Additional solubility results were used to fit the sodium-sulfate-fluoride system from $18-35^{\circ} \mathrm{C}$ so both double salts are included in the SOLGASMIX model. All coefficients used are given in Appendix A. 



\section{RESULTS AND DISCUSSIONS}

\subsection{SODIUM-NITRATE-SULFATE SYSTEM}

The sodium-nitrate-sulfate system was studied at 25 and $50^{\circ} \mathrm{C}$ in water, $1 \mathrm{~m}$ hydroxide, and $3 \mathrm{~m}$ hydroxide. As shown in Fig. 2, the $25^{\circ} \mathrm{C}$ predictions in water were made using the two different ESP databases and the SOLGASMIX model. Experimental values for the solubility of this system ${ }^{13}$ were also included in Fig. 2.

The ESP predictions based on the Public database show significant deviation from the experimental results for most of the nitrate concentration range. The Public database of the ESP could be used to predict the solubility of sodium nitrate with no sulfate present and the solubility of sodium sulfate decahydrate with no nitrate present. However, convergence difficulties were encountered during prediction of the sodium-nitrate-sulfate system when the nitrate concentration was in the range of 3-10 m. For the low nitrate concentrations, the solid phase is predicted to be sodium sulfate decahydrate. As the nitrate concentration is increased, the ionic strength increases, but the thermodynamic data in the Public database does not predict the transition from the decahydrate to anhydrous sodium sulfate. In the Public database, the lower temperature limit for the anhydrous sodium sulfate is $32.4^{\circ} \mathrm{C}$, which corresponds to the transition temperature for the pure sulfate systems. However, the transition from the sodium sulfate decahydrate to the anhydrous sodium sulfate shifts to lower temperatures when other ions such as nitrate and hydroxide are added. For the intermediate concentrations of nitrate, the ESP cannot predict the existence of the anhydrous sodium sulfate at $25^{\circ} \mathrm{C}$. The convergence problem is due to insufficient free water to form an equilibrium liquid phase. All of the water present is found as water of hydration for the decahydrate. For the high nitrate concentrations, the solid phase is predicted to be sodium nitrate.

The ESP predictions based on the Na2snacl database for anhydrous sodium sulfate are in much better agreement with the SOLGASMIX calculations and the experimental results, as shown in Fig. 2. With low nitrate concentrations, the predicted solid phase is sodium sulfate decahydrate. At a nitrate concentration of approximately $4 \mathrm{~m}$, the transition to anhydrous sodium sulfate occurs. The ESP predicts anhydrous sodium sulfate as the sole constituent in the solid phase up to the location of the invariant point at $10.3 \mathrm{~m}$ nitrate. Here, ESP predicts a liquid phase in equilibrium with a mixture of sodium nitrate and anhydrous sodium sulfate. When the nitrate concentration is greater than $10.3 \mathrm{~m}$, the stable solid phase is sodium nitrate. The ESP predictions agree well with the literature data except for the region of nitrate concentrations from 4-6 $\mathrm{m}$. The transition from the decahydrate to the anhydrous salt and the transition from the anhydrous salt to the double salt occur in this region.

In contrast to the ESP results, the SOLGASMIX predictions closely track the transitions in this region. The use of the Pitzer method for activity coefficients allows a more accurate representation, especially at higher ionic strengths. Also, inclusion of the double salt provides additional degrees of freedom in modeling, even though the predicted concentrations are similar. Finally, these data points were used directly in the regression from which SOLGASMIX parameters were obtained. 
Modifications are being initiated to include the Pitzer formalism in ESP. In addition, researchers at Hanford are conducting experiments to better quantify this phase transition as a function of temperature and ionic strength. Hopefully, these results will lead to improved predicative capabilities of ESP.

Of greater importance still are nitrate-sulfate solubilities in highly caustic solutions. No direct experimental data are available, although saltcake from Hanford tank TX-113 is high in each of these anions; ESP predictions of saltcake dissolution closely matched the Hanford experiments for this tank. For a more comprehensive evaluation, ESP calculations were compared with those of SOLGASMIX in solutions of $1 m$ and $3 m \mathrm{NaOH}$. As shown in Fig. 3, the ESP and SOLGASMIX predictions at $25^{\circ} \mathrm{C}$ are qualitatively similar, but deviate from each other in the transition region from decahydrate to anhydrous sulfate. Convergence difficulties were again encountered with the ESP in this region; their cause is under investigation. In $1 \mathrm{~m}$ hydroxide, each code mimics its pattern from Fig. 2, indicating that ESP is likely underestimating solubilities from 2-5 $m$ nitrate. In $3 \mathrm{~m}$ hydroxide, this transition occurs at a nitrate concentration less than $1 \mathrm{~m}$. Their cause is under investigation.

The ESP and SOLGASMIX codes also differed in the solubility predictions for simple salts (along the axes, where either sulfate or nitrate is zero). The points where the solubility curves intersect each axis can be compared with the solubility results in Table 1 . At $1 \mathrm{~m}$ hydroxide, both codes adequately predict the solubilities of the simple salts. For both $1 \mathrm{~m}$ and $3 m$ hydroxide the experimental values for sodium nitrate lie between the code predictions, which indicates a small degree of uncertainty for both codes. However, the ESP predictions of the sulfate solubility in $3 m$ hydroxide are noticeably low while the SOLGASMIX calculations were very close.

Table 1. Solubilities of pure salts in hydroxide solutions

\begin{tabular}{ccccc}
\hline $\begin{array}{c}\text { Temperature } \\
\left({ }^{\circ} \mathrm{C}\right)\end{array}$ & $\begin{array}{c}\text { Hydroxide } \\
\text { concentration } \\
(m)\end{array}$ & $\begin{array}{c}\text { Sulfate } \\
\text { concentration } \\
(m)\end{array}$ & $\begin{array}{c}\text { Nitrate } \\
\text { concentration } \\
(m)\end{array}$ & Solid \\
\hline 25 & 1 & 1.72 & 0 & Sodium sulfate decahydrate \\
25 & 3 & 1.79 & 0 & Sodium sulfate decahydrate \\
25 & 1 & 0 & 9.67 & Sodium nitrate \\
25 & 3 & 0 & 7.73 & Sodium nitrate \\
50 & 0 & 3.27 & 0 & Anhydrous sodium sulfate \\
50 & 1 & 2.41 & 0 & Anhydrous sodium sulfate \\
50 & 3 & 1.29 & 0 & Anhydrous sodium sulfate \\
\hline
\end{tabular}




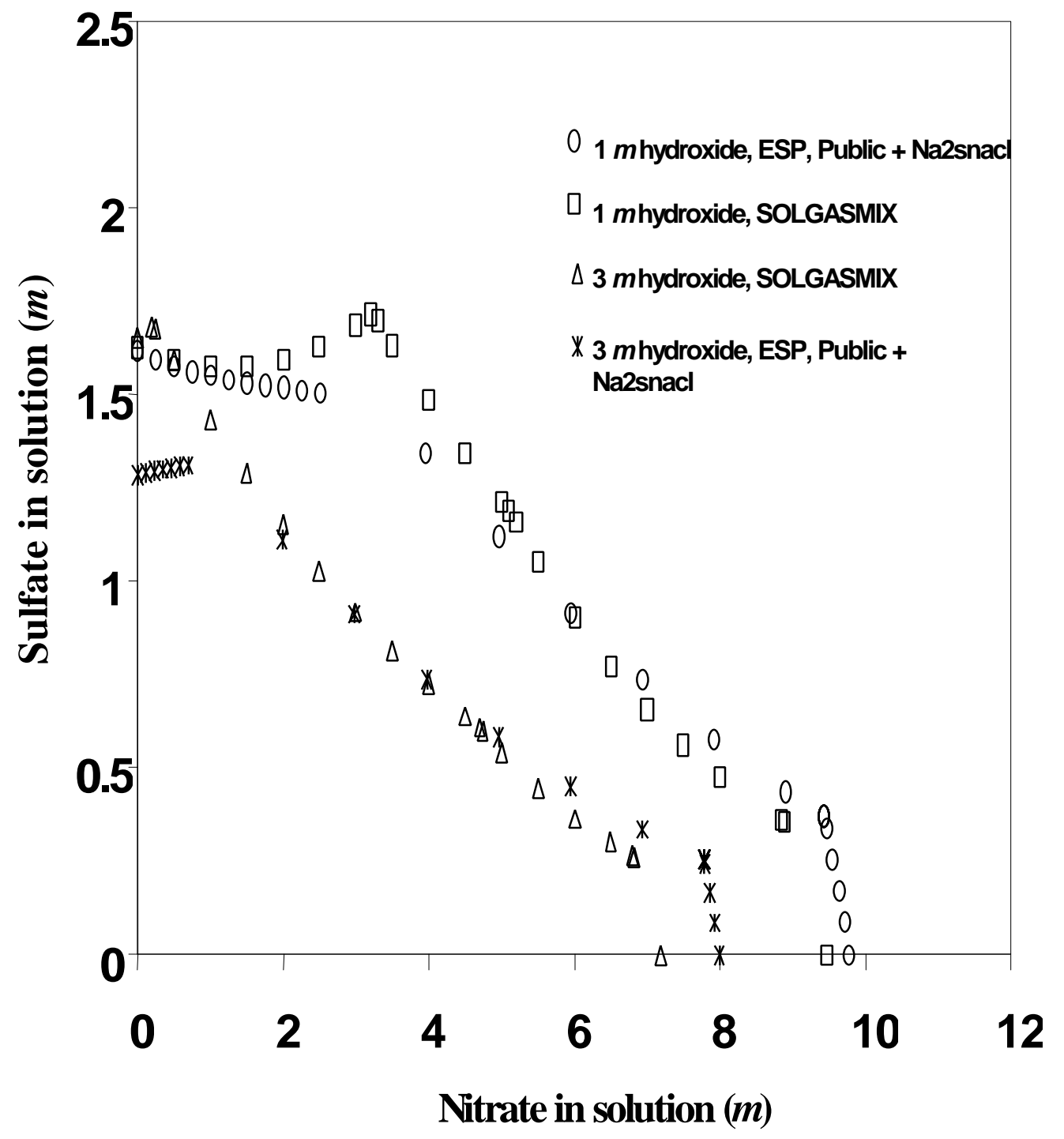

Fig. 3. Solubility envelope for the sodium-nitrate-sulfate system at $25^{\circ} \mathrm{C}$ in $1-3 \mathrm{~m}$ hydroxide solutions. 
The ESP and SOLGASMIX predictions for the sodium-nitrate-sulfate system were also conducted at $50^{\circ} \mathrm{C}$, as shown in Fig. 4 for hydroxide concentrations of 0,1 , and $3 \mathrm{~m}$. At this higher temperature, the equilibrium crystalline phase is anhydrous sodium sulfate in the regions of low and moderate nitrate. The experimental results indicate a small region of double salt formation, which has very little impact on the shape of the solubility curves. Even though the database for SOLGASMIX includes the double salt, the code did not predict the formation of the double salt under these conditions. This discrepancy could be due to uncertainties in the code calculations or in the experimental results, or both.

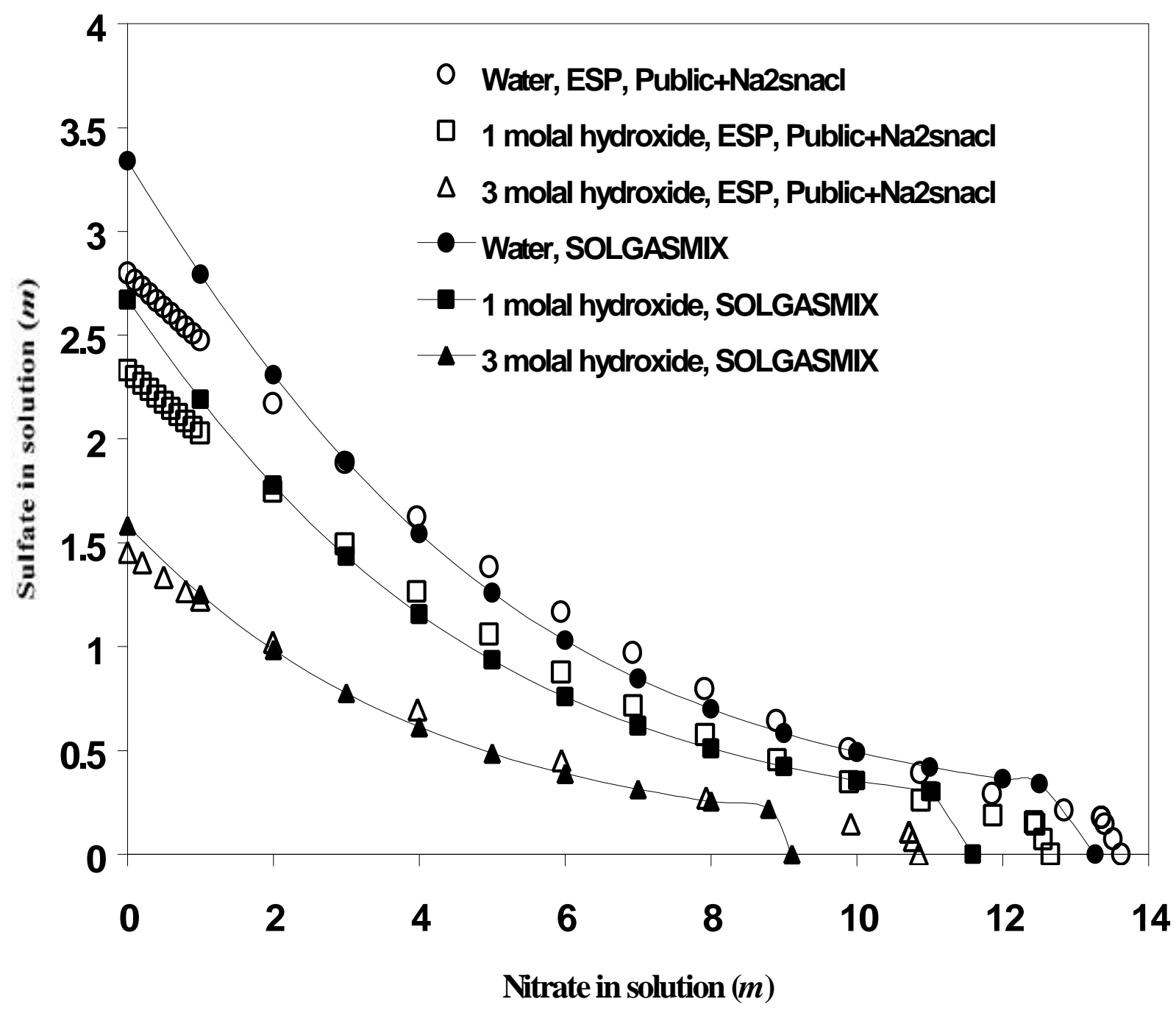

Fig. 4. ESP and SOLGASMIX predictions for the sodium-nitrate-sulfate system at $50^{\circ} \mathrm{C}$. 
Both codes indicate a decrease in solubility as the nitrate concentration increases. The codes differ primarily in the pure component sulfate solubility and in the curvature of the solubility lines. With respect to the sulfate solubility, the SOLGASMIX calculations in pure water are superior, while the ESP results are closer in 1 and $3 m$ hydroxide. With respect to curvature, the SOLGASMIX predictions closely match the experimental results in the absence of hydroxide. Since SOLGASMIX utilizes the Pitzer model for activity coefficients, it can use mixture parameters to improve the modeling of the curvature in phase equilibria.

\subsection{SODIUM-FLUORIDE-SULFATE SYSTEM}

For the sodium-fluoride-sulfate system, a comparison of the ESP predictions with the SOLGASMIX calculations and experimental results ${ }^{3}$ is shown in Fig. 5. In water, ESP substantially underestimates the equilibrium solubility while the SOLGASMIX predictions closely match the literature values. The SOLGASMIX comparison is not surprising as the experimental results were used to develop the model parameters for the SOLGASMIX program. In 1-3 $m$ hydroxide solutions, the ESP and SOLGASMIX predictions matched for the formation of the double salt, although ESP underestimated solubility for sodium fluoride with no sulfate present. A similar difficulty was observed for sodium fluoride in the sodium-fluoride-phosphate system. 9 The ESP predictions for the solubility of sodium fluoride were improved by using the free energy of formation instead of the standard KFIT expression. (The KFIT routine is the default recommended by OLI, Inc. to describe the solid-liquid equilibrium.) The use of the free energy of formation in the ESP did not alter the other portions of the solubility curve.

The KFIT expression for the fluoride-sulfate double salt does not include its temperature dependence. However, as shown in Fig. 6, the ESP predictions at $50^{\circ} \mathrm{C}$ closely match the SOLGASMIX curves, which did include temperature dependence. The solubilities of sodium sulfate and sodium fluoride change very little from $30-100^{\circ} \mathrm{C}$, and apparently, the same pattern holds for the sodium fluorosulfate double salt as well. 


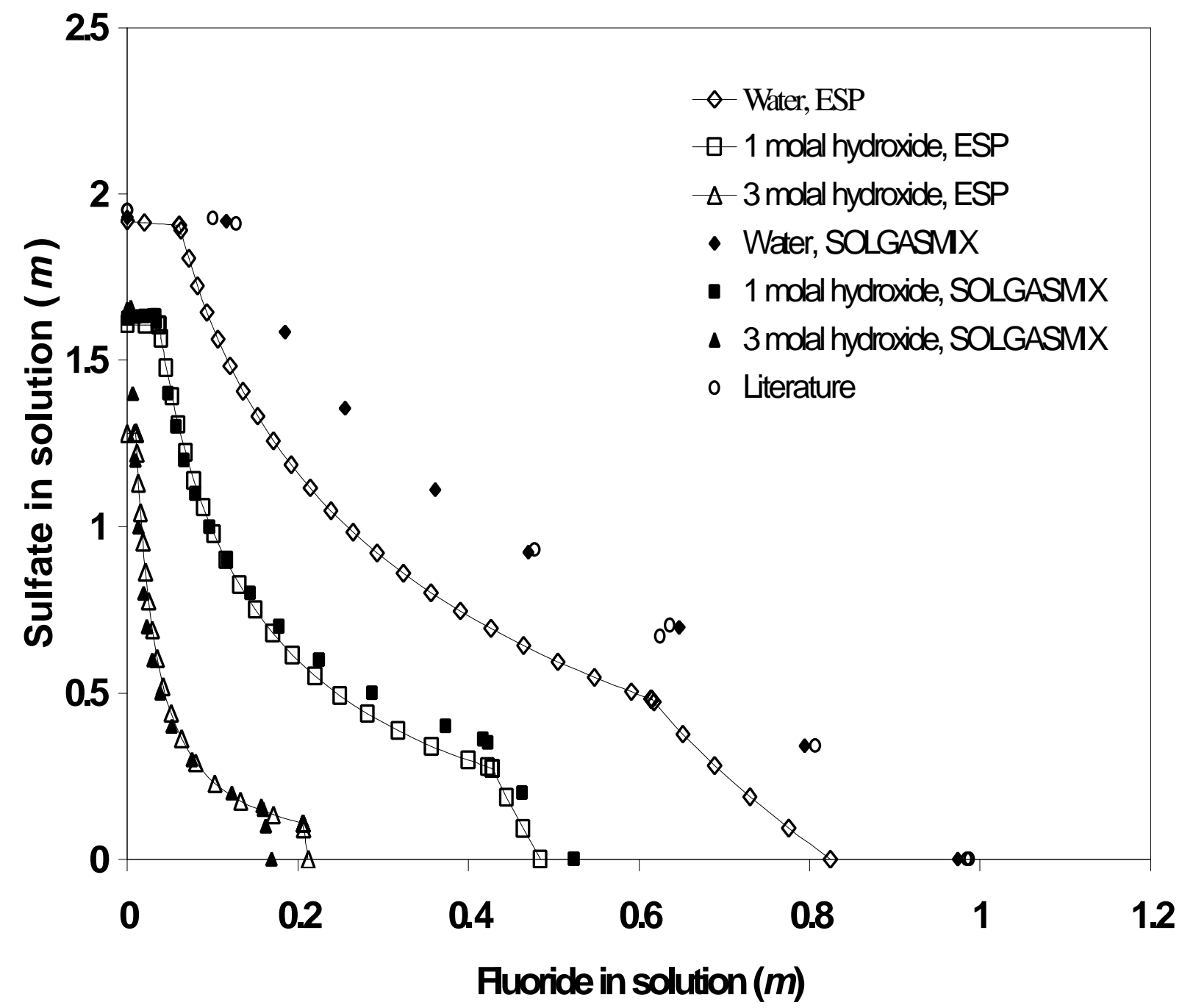

Fig. 5. Comparison of the solubility envelope for the sodium-fluoride-sulfate system at $25^{\circ} \mathrm{C}$. 


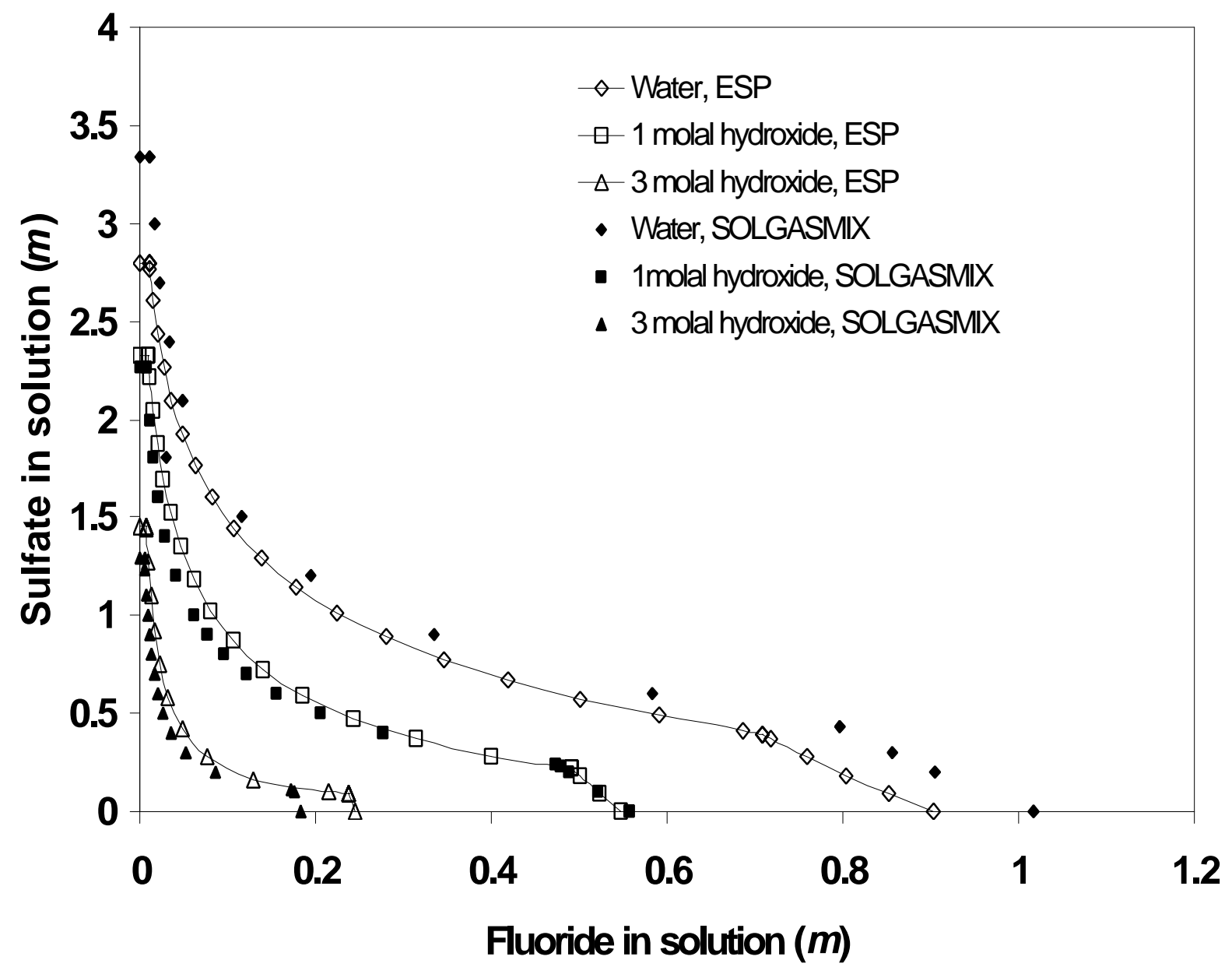

Fig. 6. Comparison of the solubility envelope for the sodium-fluoride-sulfate system at $50^{\circ} \mathrm{C}$. 



\section{SUMMARY AND CONCLUSIONS}

ESP continues to adequately predict the solubility of most key chemical systems in the Hanford tank waste. For example, the ESP predictions were in fair agreement with the solubility experiments for the fluoride-phosphate system, although ESP probably underestimates the aqueous amounts. Due to the importance of this system in the formation of pipeline plugs, additional experiments have been made at elevated temperatures, 9 and improvements to the ESP database will be made. ESP encountered problems with sulfate systems because the Public database for ESP does not include anhydrous sodium sulfate in mixed solutions below $32.4^{\circ} \mathrm{C}$. This limitation leads to convergence problems and to spurious predictions of solubility near the transition point with sodium sulfate decahydrate when other salts such as sodium nitrate are present. However, ESP was able to make reasonable solubility predictions with a corrected database, demonstrating the need to validate and document the various databases that can be used by ESP.

Even though ESP does not include the sulfate-nitrate double salt, this omission does not appear to be a major problem. The solubility predictions with and without the sulfate-nitrate double salt are comparable. In sharp contrast, the sulfate-fluoride double salt is included, but ESP still underestimates solubility in some cases. This problem can misrepresent the ionic strength of the solution, which is an important factor in the formation of pipeline plugs. Solubility tests on the sulfate-fluoride system are planned to provide additional data at higher temperatures and in caustic solutions. These results will be used to improve the range and accuracy of ESP predictions.

ESP will continue to provide important predictions for waste processing operations while being evaluated and improved. For example, ESP will be used to determine the amount of water for the saltcake dissolution efforts at Hanford. When ESP underestimates the solubility of key systems, the RPP may be required to use more water than necessary. This additional water will be problematic due to limited tank space and to additional waste to process. 



\section{REFERNCES}

1. N. G. Colton, E. A. Daymo, W. L. Kuhn, and A. R. Felmy, Literature Review: Events, Phenomena, and Studies Pertinent to Technical Risks in the Waste Feed Delivery Project, Pacific Northwest National Laboratory, Richland, Washington, 1998.

2. E. C. Beahm, C. F. Weber, D. D. Lee, T. A. Dillow, R. D. Hunt, C. M. Keswa, K. OsseoAsare, and K. E. Spear, Status Report on Solid Control in Leachates, ORNL/TM13660, Lockheed Martin Energy Research Corp., Oak Ridge National Laboratory, July 1998.

3. R. D. Hunt, T. A. Dillow, J. R. Parrott, Jr., T. D. Welch, and C. F. Weber, Waste Preparation and Transport Chemistry: Results of the FY 2000 Studies, ORNL/TM2000/?, UT-Battelle, LLC, Oak Ridge National Laboratory, 2000.

4. C. F. Weber, E. C. Beahm, and J. S. Watson, "Modeling Thermodynamics and Phase Equilibria for Aqueous Solutions of Trisodium Phosphate," J. Sol. Chem. 28(11), 1207, 1999.

5. C. F. Weber, E. C. Beahm, D. D. Lee, and J. S. Watson, “A Solubility Model for Aqueous Solutions Containing Sodium, Fluoride, and Phosphate Ions," Ind. Eng. Chem. Res. 39, 518, 2000.

6. G. Eriksson, "Thermodynamic Studies of High Temperature Equilibria," Chem. Scripta, 8, 100, 1975.

7. C. F. Weber, "Convergence of the Equilibrium Code SOLGASMIX," J. Comp. Phys., 145, 665, 1998.

8. K. S. Pitzer, Activity Coefficients in Electrolyte Solutions, CRC Press, Boca Raton, Florida, 1991.

9. R. K.Toghiani and J. S.Lindner, Saltcake Dissolution Studies: FY99 Status Report, Diagnostic Instrumentation and Analysis Laboratory, Starkville, Mississippi, 2000.

10. E. C. Beahm, R. K. Toghiani, and C. F. Weber, Comparative Calculations of Solubility Equilibria, ORNL/TM-1999/127, UT-Battelle, LLC, Oak Ridge National Laboratory, July 2000 .

11. D. L. Herting, Saltcake Dissolution FY 2000 Status Report, HNF-7031, Fluor Hanford, Richland, Washington, 2000. 
12. R. D. Hunt, E. C. Beahm, C. W. Chase, J. L. Collins, T. A. Dillow, and C. F. Weber, Prevention of Solids Formation; Results of the FY 1999 Studies, ORNL/TM1999/263, Lockheed Martin Energy Research Corp., Oak Ridge National Laboratory, December 1999.

13. W. F. Linke, Solubilities, $4^{\text {th }}$ ed., American Chemical Society, Washington, DC, 1965.

14. Outokumpu Research, HSC Chemistry for Windows, Version 2.0, 1994. 


\section{APPENDIX A}

\section{Parameters for SOLGASMIX Model}





\section{Appendix A}

\section{Parameters for SOLGASMIX Model}

All parameters are temperature dependent according to the functional form

$$
\mathrm{F}(\mathrm{T})=\mathrm{A}+\mathrm{B}\left(\mathrm{T}-\mathrm{T}_{0}\right)+\mathrm{C}\left(1 / \mathrm{T}_{0}-1 / \mathrm{T}\right)+\mathrm{D} \ln \left(\mathrm{T} / \mathrm{T}_{0}\right)+\mathrm{E}\left(\mathrm{T}^{2}-\mathrm{T}_{0}{ }^{2}\right)
$$

Table A.1. Coefficients for Gibbs energy of formation

\begin{tabular}{|c|c|c|c|c|c|}
\hline & $\mathbf{A}$ & $\mathbf{B}$ & $\mathbf{C}$ & $\mathbf{D}$ & $\mathbf{E}$ \\
\hline $\mathrm{H}_{2} \mathrm{O}$ & -95.665 & -1.0029 & 0 & 324.04 & 0.000508 \\
\hline $\mathrm{Na}^{+}$ & -105.73 & 0.85194 & 0 & 0 & -0.00088 \\
\hline $\mathrm{NO}_{3}^{-}$ & -43.984 & 0.68002 & 0 & 0 & -0.00067 \\
\hline $\mathrm{OH}^{?}$ & -63.534 & 0.75606 & 0 & 0 & -0.00075 \\
\hline $\mathrm{F}^{?}$ & -112.59 & 1.1322 & 0 & 0 & -0.00114 \\
\hline $\mathrm{PO}_{4}^{3-}$ & -411.192 & 4.33069 & 0 & 0 & -0.00436 \\
\hline $\mathrm{HPO}_{4}^{2-}$ & -439.592 & 4.74018 & 0 & 0 & -0.005 \\
\hline $\mathrm{SO}_{4}^{2-}$ & -300.531 & 3.11291 & 0 & 0 & -0.00316 \\
\hline $\mathrm{Na}_{2} \mathrm{SO}_{4}$ & -513.057 & 4.78648 & 0 & 0 & -0.0049 \\
\hline $\mathrm{Na}_{2} \mathrm{SO}_{4} * 10 \mathrm{H}_{2} \mathrm{O}$ & -1472.02 & 15.5281 & 0 & 0 & -0.01624 \\
\hline $\mathrm{Na}_{2} \mathrm{SO}_{4} * \mathrm{NaNO}_{3} * 2 \mathrm{H}_{2} \mathrm{O}$ & -852.691 & 8.84139 & 0 & 0 & -0.00932 \\
\hline $\mathrm{Na}_{2} \mathrm{SO}_{4} * \mathrm{NaF}$ & -852.691 & 8.84139 & 0 & 0 & -0.00932 \\
\hline
\end{tabular}


Table A.2. Coefficients for Pitzer parameters

\begin{tabular}{|c|c|c|c|c|c|c|c|}
\hline Species & & & Parameter & $\mathbf{A}$ & B & $\mathbf{C}$ & D \\
\hline $\mathrm{Na}^{+}$ & $\mathrm{NO}_{3}^{-}$ & & $\beta^{(0)}$ & 0.00204 & 0 & 406.5 & -1.04 \\
\hline $\mathrm{Na}^{+}$ & $\mathrm{NO}_{3}^{-}$ & & $\beta^{(1)}$ & 0.2368 & 0 & 712.4 & -1.214 \\
\hline $\mathrm{Na}^{+}$ & $\mathrm{NO}_{3}^{-}$ & & C & 0.00008 & 0 & -27.22 & 0.0756 \\
\hline $\mathrm{Na}^{+}$ & $\mathrm{OH}^{-}$ & & $\beta^{(0)}$ & 0.0864 & 0 & 531.5 & -1.625 \\
\hline $\mathrm{Na}^{+}$ & $\mathrm{OH}^{-}$ & & $\beta^{(1)}$ & 0.253 & 0 & 894.4 & -2.7478 \\
\hline $\mathrm{Na}^{+}$ & $\mathrm{OH}^{-}$ & & C & 0.0021 & 0 & -40.69 & 0.1158 \\
\hline $\mathrm{Na}^{+}$ & $\mathrm{F}^{-}$ & & $\beta^{(0)}$ & 0.033 & 0 & 246.8 & -0.6728 \\
\hline $\mathrm{Na}^{+}$ & $\mathrm{F}^{-}$ & & $\beta^{(1)}$ & 0.2456 & 0 & 2833 & -9.451 \\
\hline $\mathrm{Na}^{+}$ & $\mathrm{F}^{-}$ & & C & 0.00281 & 0 & 12.25 & -0.0436 \\
\hline $\mathrm{Na}^{+}$ & $\mathrm{PO}_{4}{ }^{3-}$ & & $\beta^{(0)}$ & 0.2534 & 0 & 130.3 & 0.1247 \\
\hline $\mathrm{Na}^{+}$ & $\mathrm{PO}_{4}^{3-}$ & & $\beta^{(1)}$ & 3.7384 & 0 & 23420 & -70.37 \\
\hline $\mathrm{Na}^{+}$ & $\mathrm{PO}_{4}^{3-}$ & & C & -0.0226 & 0 & & -0.00016 \\
\hline $\mathrm{Na}^{+}$ & $\mathrm{HPO}_{4}{ }^{2-}$ & & $\beta^{(0)}$ & -0.03045 & 0 & 1826 & -5.159 \\
\hline $\mathrm{Na}^{+}$ & $\mathrm{HPO}_{4}{ }^{2-}$ & & $\beta^{(1)}$ & 1.3504 & 0 & 6023 & -18.77 \\
\hline $\mathrm{Na}^{+}$ & $\mathrm{HPO}_{4}{ }^{2-}$ & & C & 0.00359 & 0 & -282.6 & 0.8267 \\
\hline $\mathrm{Na}^{+}$ & $\mathrm{SO}_{4}^{2-}$ & & $\beta^{(0)}$ & -0.01358 & 0 & 654 & -1.691 \\
\hline $\mathrm{Na}^{+}$ & $\mathrm{SO}_{4}^{2-}$ & & $\beta^{(1)}$ & 0.6998 & 0 & 1143 & -2.164 \\
\hline $\mathrm{Na}^{+}$ & $\mathrm{SO}_{4}^{2-}$ & & C & 0.00394 & 0 & -37.95 & 0.0955 \\
\hline $\mathrm{NO}_{3}^{-}$ & $\mathrm{OH}^{-}$ & & $\theta$ & -0.0547 & & & \\
\hline $\mathrm{NO}_{3}^{-}$ & $\mathrm{SO}_{4}{ }^{2-}$ & & $\theta$ & 0.0673 & & & \\
\hline $\mathrm{OH}^{-}$ & $\mathrm{F}^{-}$ & & $\theta$ & 0.1193 & & & \\
\hline $\mathrm{OH}^{-}$ & $\mathrm{PO}_{4}{ }^{3-}$ & & $\theta$ & & & & \\
\hline $\mathrm{OH}^{-}$ & $\mathrm{SO}_{4}{ }^{2-}$ & & $\theta$ & -0.013 & & & \\
\hline $\mathrm{F}^{-}$ & $\mathrm{PO}_{4}{ }^{3-}$ & & $\theta$ & 0.55 & & & \\
\hline $\mathrm{Na}^{+}$ & $\mathrm{NO}_{3}^{-}$ & $\mathrm{OH}^{-}$ & $\psi$ & 0.0002 & & & \\
\hline $\mathrm{Na}^{+}$ & $\mathrm{NO}_{3}^{-}$ & $\mathrm{SO}_{4}{ }^{2-}$ & $\psi$ & 0.00335 & & & \\
\hline $\mathrm{Na}^{+}$ & $\mathrm{OH}^{-}$ & $\mathrm{F}^{-}$ & $\psi$ & -0.035 & & & \\
\hline $\mathrm{Na}^{+}$ & $\mathrm{OH}^{-}$ & $\mathrm{PO}_{4}^{3-}$ & $\psi$ & 0.03 & & & \\
\hline $\mathrm{Na}^{+}$ & $\mathrm{OH}^{-}$ & $\mathrm{SO}_{4}^{2-}$ & $\psi$ & -0.009 & & & \\
\hline $\mathrm{Na}^{+}$ & $\mathrm{F}^{-}$ & $\mathrm{PO}_{4}^{3-}$ & $\psi$ & & & & \\
\hline $\mathrm{Na}^{+}$ & $\mathrm{F}^{-}$ & $\mathrm{HPO}_{4}{ }^{2-}$ & $\psi$ & & & & \\
\hline
\end{tabular}


ORNL/TM-2000/317

\section{INTERNAL DISTRIBUTION}

1. W. C. Carter

2. A. G. Croff

3. M. B. Emmett

4-8. R. D. Hunt

9. R. T. Jubin

10. M. A. Kuliasha

11. C. P. McGinnis

12. G. McNeese
12. J. S. Watson

13-17. C. F. Weber

18. T. D. Welch

19. R. M. Westfall

20. Central Research Library

21-22. ORNL Laboratory Records (OSTI)

23. ORNL Laboratory Records

\section{EXTERNAL DISTRIBUTION}

24. Hani Al Habbash, 205 Research Boulevard, Starkville, MS 39759-9734

25. Harry Babad, Babad Technical Services, 2540 Cordoba Court, Richland, WA 99352

26. Joe Cruz, Department of Energy, Office of River Protection, P.O. Box 550, MISN H6! 60, Richland, WA 99352

27. John Garfield, Numatec Hanford Company, P.O. Box 1300, MSIN R3! 73, Richland, WA 99352

28. Ken Gasper, CH2M Hill Hanford Group, P.O. Box 1500, MSIN H6! 19, Richland, WA 99352

29. Dan Herting, Fluor Daniel, P.O. Box 1970, MSIN T6! 07, Richland, WA 99352

30. Jim Honeyman, CH2M Hill Hanford Group, P.O. Box 1500, MSIN H6! 62, Richland, WA 99352

31. Albert Hu, CH2M Hill Hanford Group, P.O. Box 1300, MSIN R2! 11, Richland, WA 99352

32. James Jewett, Numatec Hanford Company, P.O. Box 1300, MSIN R3! 73, Richland, WA 99352

33. Randy Kirkbride, Numatec Hanford Company, P.O. Box 1300, MSIN R3! 73, Richland,WA 99352

34. Jeff Lindner,DIAL, 205 Research Boulevard, Starkville, MS 39759-9734

35. Graham MacLean, FFS, P.O. Box 1050, MSIN G3! 10, Richland, WA 99352

36. Yasuo Onishi, Pacific Northwest National Laboratory, P.O. Box 999, MISN K7! 15, Richland, WA 99352

37. Wally Schulz, W2S Company, 12704 Sandia Ridge Place, NE, Albuquerque, NM 87111

38. Tanks Focus Area Headquarters Program Lead, c/o Kurt Gerdes, DOE Office of Science and Technology, 19901 Germantown Road, 1154 Cloverleaf Building, Germantown, MD 20874-1290

39. Tanks Focus Area Program Manager, c/o T.P. Pietrok, U.S. Department of Energy, Richland Operations Office, P.O. Box 550, MSIN K8! 50, Richland, WA 99352 
40-48. Tanks Focus Area Technical Team, c/o B.J. Williams, Pacific Northwest National Laboratory, P.O. Box 999, MISN K9! 69, Richland, WA 99352

49. Becky Toghiani, Mississippi State University, School of Chemical Engineering, P.O. Box 9595, MS State, MS 39762

50. Joe Westsik, Pacific Northwest National Laboratory, P.O. Box 999, MISN K9! 91, Richland, WA 99352 